\title{
Evaluation of the efficacy and safety of the mechanical displacement in the esophageal heating prevention during atrial fibrillation radiofrequency ablation.
}

\author{
RICARDO AMARANTE ${ }^{1}$, José Carlos Mateos ${ }^{2}$, Tasso Lobo ${ }^{1}$, Tomás Pena ${ }^{1}$, Juan Zerpa ${ }^{3}$, \\ Carlos Pachón $^{1}$, Felipe Ortêncio ${ }^{1}$, Thiago Guimarães Osório ${ }^{4}$, Maria Zelia Pachon ${ }^{1}$, Juan \\ Pachon $^{1}$, and Enrique Indalecio Pachon ${ }^{1}$ \\ ${ }^{1}$ Hospital do Coração \\ ${ }^{2}$ São Paulo Cardiology Institute Pacemaker Service \\ ${ }^{3}$ Heart Hospital, Sao Paulo, \\ ${ }^{4}$ Heart Rhythm Management Center, Cardiovascular Center UZ Brussel Vrij Universiteit \\ Brussel, Dpt Cardiology laarbeeklaan 101 Brussel, Jette, BE 1090 0032-2-4763038, \\ Cardiology Brussels, BE 0032-2-4763038
}

August 23, 2020

\begin{abstract}
Introduction: As the pulmonary vein isolation (PVI) is the cornerstone of the atrial fibrillation (AF) ablation procedure, esophagus overheating has become a subject of great concern. Objectives: To assess whether the mechanical displacement of the esophagus (MDE), performed by a regular transesophageal echocardiogram probe (TEEP) may prevent esophagus overheating during the procedure. Methods: A 55 patient prospective-controlled study with paroxysmal or persistent AF in which RF delivery was stopped, whenever a sinusoidal probe with multiple thermocouples detected a luminal esophageal temperature (LET) elevation [?]0.5 ${ }^{\circ} \mathrm{C}$. A LET elevation $<0.5^{\circ} \mathrm{C}$ during RF delivery was considered the successful endpoint after performed the MDE. In some patients, diluted barium was instilled to highlight the esophagus boundaries. Esophagogastroduodenoscopy (EGD) was performed if there were any sign or symptom of esophagus injury after the procedure. Results: The MDE was necessary in 47 of the 55 subjects enrolled to correct LET elevation ([?]0.5degC). After the MDE, 41 of those 47 patients had a LET elevation $<0.5 \mathrm{degC}$, and none of them, had a LET elevation [?]38.5degC. The average basal LET was 35.71 +- 0.12degC. Immediately before the MDE, the average LET was $37.03+-0.06 \mathrm{degC}$ and post-displacement was $35.83+-0.08 \mathrm{degC}$. The displacement range average was $2.25+-1.19 \mathrm{~cm}$ (maximum: $6.17 \mathrm{~cm}$ ). After displacement, $100 \%$ of the esophagus remained in the same position. Of the total 14 patients who underwent EGD, 6 were normal, erosion was detected in 1 and superficial hematoma in 7. Conclusion: the MDE was effective and safe in preventing its overheating during RF catheter AF ablation.
\end{abstract}

\section{Hosted file}

MDE JCI_16_8_20.docx available at https://authorea.com/users/352032/articles/477143evaluation-of-the-efficacy-and-safety-of-the-mechanical-displacement-in-the-esophagealheating-prevention-during-atrial-fibrillation-radiofrequency-ablation 